\title{
Investigation of Structure and Physical-Mechanical Properties of Metal in Different Zones of Welded Trunk Pipelines Made of X80 Strength Grade Steel
}

\author{
Evgeniia Putilova ${ }^{1, a,{ }^{*},}$, Sergey Zadvorkin ${ }^{1}$ and Kristina Kryucheva ${ }^{1}$ \\ ${ }^{1}$ Institute of Engineering Science, Ural Branch of the Russian Academy of Sciences (IES UB \\ RAS), 620049, 34 Komsomolskaya st., Ekaterinburg, Russia \\ atuevaevgenya@mail.ru
}

Keywords: High-Strength Pipe Steel, Steel Grade X80, Structure, Properties, NonDestructive Magnetic Testing

\begin{abstract}
The development of trunk pipelines network, taking into accont their operation in difficult climatic conditions, leads to the creation and the development of non-destructive testing methods to control the stress-strain state of the pipe itself, as well as welded joints. This work presents the results of studies of the microstructure, as well as the mechanical and magnetic characteristics of the metal cut from different zones of the welded joint of X80 strength class pipe steel.
\end{abstract}

\section{Introduction}

The use of high-strength pipe steels with strength grade X80 and higher, can reduce the metal consumption of main gas pipelines and reduce costs during their construction [1]. Currently, highstrength pipe steels of strength grade X80 are increasingly used in the construction of gas pipelines in areas with harsh climatic conditions and unstable soils, including seismic zones [2-5].

It is well known that most often the centers of destruction of metal structures, including main pipelines, are precisely welded joints, in particular the heat-affected zone (HAZ). Violation of the strength of welded joints of pipelines occurs because of the two main reasons. The first one is the presence of defects. And the second - due to the action of stresses [6-9].

Several zones could be distinguished in welded structures: the base metal, the weld and the HAZ. Differences in their structure, physical and mechanical properties, and the level of residual stresses determine the fact that in the process of manufacturing and operation, the material of different sections of welded structures will react differently to the action of applied loads. In this regard, the development of methods for assessing changes in the stress-strain state in various zones of welded steel structures at the stages of their manufacture and operation is an urgent problem of non-destructive testing.

In this work, we investigated the structure and mechanical and magnetic properties of the metal of various zones of the welded joint of steel of strength grade X80 under the conditions of applied loads in order to determine the possibility of using magnetic methods to assess the changes occurring in the material of welded pipes of large diameter during manufacture and operation.

\section{Materials and methods}

The studies were carried out on samples cut along the rolling direction, i.e. along the weld joint, from base metal, HAZ material and weld metal. This pipe steel was produced by controlled rolling method and with the strength grade of X80 (1420 mm diameter and $21.6 \mathrm{~mm}$ wall thickness) (according to API standard). Samples cut from the HAZ material were cut at a distance of about $10 \mathrm{~mm}$ from the weld. The chemical composition of the investigated materials is given in Table 1. 
The appearance of the welded joint is shown in Fig. 1. Dotted lines in fig. 1 these are the lines along which the microhardness distribution was measured. The microhardness HV0.05 of the samples in the cross section was determined on a Shimadzu microhardness tester with a load on the indenter of $0.49 \mathrm{~N}$. The results of microhardness measurements will be shown below on Fig. 4.

To carry out microstructural studies, thin sections were prepared on the cross section of the samples. The microstructure of the obtained samples was investigated using optical and electron microscopy techniques, as well as by electron backscattered diffraction (EBSD analysis). To perform these tasks, a NEOPHOT-21 optical microscope and a Tescan scanning electron microscope equipped with Advanced AZtecHKL diffraction (EBSD) analysis system were used.

Table 1. Chemical composition of the investigated materials (mas. \%)

\begin{tabular}{|l|l|l|l|l|l|l|l|l|l|l|l|}
\hline Zone & $\mathrm{C}$ & $\mathrm{Si}$ & $\mathrm{Mn}$ & $\mathrm{P}$ & $\mathrm{S}$ & $\mathrm{Cr}$ & $\mathrm{Ni}$ & $\mathrm{Mo}$ & $\mathrm{Nb}$ & $\mathrm{V}$ & $\mathrm{Ti}$ \\
\hline $\begin{array}{l}\text { Base } \\
\text { metal } \\
\text { and }\end{array}$ & 0,083 & 0,21 & 1,77 & 0,009 & 0,001 & 0,101 & 0,243 & 0,144 & 0,040 & 0,002 & 0.009 \\
$\begin{array}{l}\mathrm{HAZ} \\
\text { metal }\end{array}$ & & & & & & & & & & & \\
\hline $\begin{array}{l}\text { Weld } \\
\text { material }\end{array}$ & 0,077 & 0,35 & 1,66 & 0,011 & 0,002 & 0,079 & 0,286 & 0,338 & 0,02 & 0,003 & 0.011 \\
\hline
\end{tabular}

Mechanical properties (yield stress $\sigma_{\mathrm{Y}}$, ultimate strength $\sigma_{\mathrm{U}}$, relative elongation $\delta$ and relative contraction $\psi$ ) of the materials under the study were determined in accordance with GOST 149784 by carrying out uniaxial tensile tests of longitudinal specimens on a Tinius Olsen SL-60 testing machine at room temperature. The tensile elongation of the samples was determined contactlessly using a La Vision video extensometer.

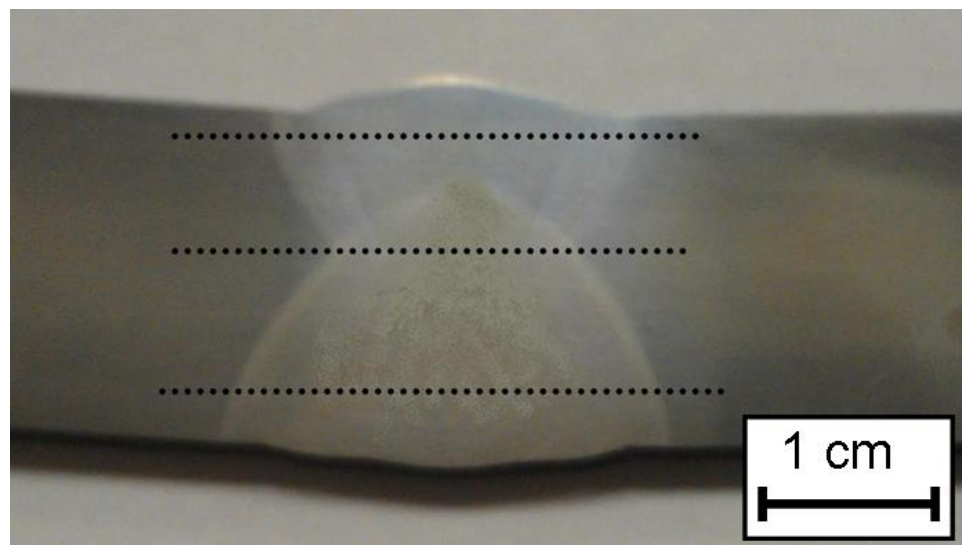

Fig. 1. The appearance of the investigated welded joint of steel of strength class X80

The influence of elastic deformation according to the uniaxial tension scheme on the behavior of the magnetic characteristics of the metal of separate zones of the welded joint of steel of strength class X80 was investigated.

The tests were carried out at room temperature on a universal testing machine with a maximum tensile force of $50 \mathrm{kN}$. Upon reaching a certain degree of deformation, the loading process was suspended without unloading the sample, and magnetic hysteresis loops were recorded using a Remagraph C-500 magnetic measuring complex. Magnetic measurements were carried out in a 
closed magnetic circuit according to the permeameter scheme. A magnetic field with an intensity of up to $500 \mathrm{~A} / \mathrm{cm}$ was applied along the axis of the sample. The values of the coercive force $H_{\mathrm{c}}$, residual induction $B_{\mathrm{r}}$, and maximum magnetic permeability $\mu_{\max }$ were determined from the magnetic hysteresis loops. The error in measuring the field and induction did not exceed $3 \%$. Before and after each measurement of the magnetic properties, the sample was demagnetized. By differentiating the descending branches of the magnetic hysteresis loops, the field dependences of the differential magnetic permeability $\mu_{\text {diff }}$ were obtained.

\section{Results and its discussion}

The results of metallographic studies are shown in Fig. 2.

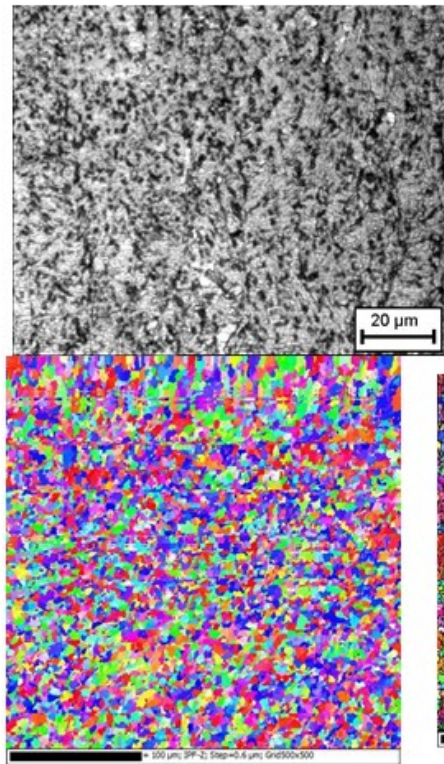

a)

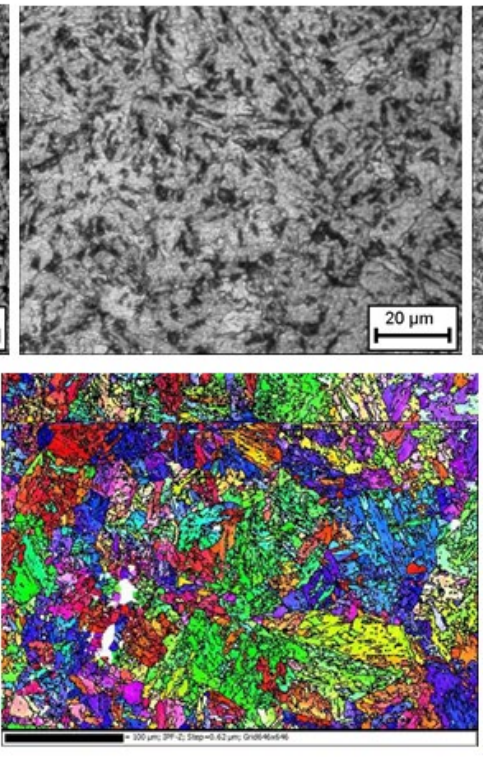

b)

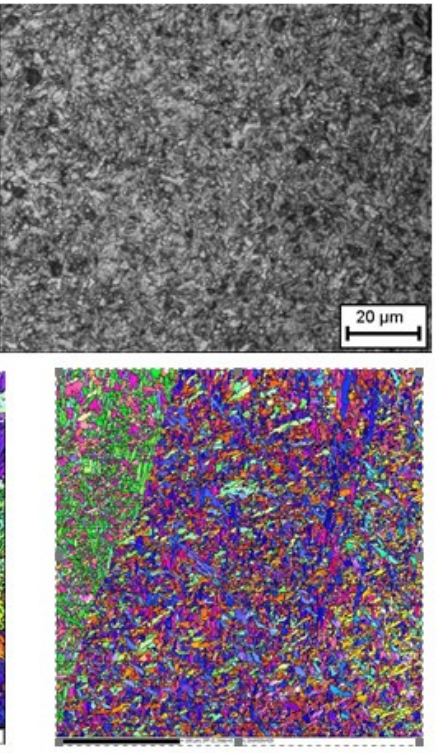

c)

Fig. 2. Microstructure of steel with the strength grade X80: $a$-Base metal; $b-H A Z$ metal; $c$ weld material.

The structure of the base metal of a pipe made of steel of strength grade X80 consists of a mixture of fine quasi-polygonal ferrite, and globular bainite (see Fig. 2a). As it is shown in [10], to create steel with such a morphology, a fine austenite grain structure should be formed, which is achieved by microalloying of niobium, vanadium, and titanium. $\mathrm{Nb}, \mathrm{V}$ and $\mathrm{Ti}$ leads to the formation of carbides that contribute to precipitation hardening of steel [1]. For steels of strength grades X80-X100, and higher a fine-dispersed structure mostly consists of bainite, sometimes ferrite and bainite [1] is characteristically. And such structure helps to achieve high strength and good cold resistance even at large thicknesses of rolled products. But to get these some conditions have to be met $[2,10]$ : reduction of carbon content $(0.04-0.08 \%)$; the introduction of such alloying elements $\mathrm{Mn}, \mathrm{Mo}, \mathrm{Ni}, \mathrm{Cr}, \mathrm{Cu}$; complex microalloying with $\mathrm{Nb}, \mathrm{Ti}, \mathrm{V}$; reduction of the content of harmful impurities $(\leq 0.002 \% \mathrm{~S} ; \leq 0.010 \% \mathrm{P})$; the use of accelerated cooling after rolling in controlled modes.

The HAZ material of the studied steel is characterized by the presence of a zone of coarser grain (Fig.2b). The reason for the appearance of a coarse-grained structure immediately adjacent to the fusion line is heating to temperatures at which the majority of carbide particles dissolve, which are effective barriers to inhibiting grain growth [11]. In addition to lath bainite, the structure contains acicular and globular bainite. The weld material (Fig. 2c) of steel of strength class X80 is 
characterized by greater dispersion in comparison with the base metal and HAZ material, and has such components as acicular bainite, ferrite and martensite-austenitic component. Due to the greater dispersion and differences in the chemical composition (see Table 1) of the weld material, the hardness of the weld material exceeds the values of the hardness of the base metal and the HAZ material (see Table 2). Fig. 2 also demonstrates the results of EBSD analysis of the investigated materials. And it is obvious that all the conclusions made from the optical microscopy is proved by these pictures.

Table 2 shows the mechanical (strength, microhardness and plasticity) and magnetic (coercitive force, remanente, maximal magnetic permeability, and saturation magnetization), characteristics of the metal of various zones of the welded pipe. For a pipe made of steel of strength class X80, the strength characteristics $\left(\sigma_{\mathrm{Y}}\right.$ and $\left.\sigma_{\mathrm{U}}\right)$ of the weld metal are almost $10 \%$ higher than the similar characteristics of the base metal. Different zones of the welded joint of pipes have practically the same value of $\sigma_{Y} / \sigma_{U}$, which indicates the equal strength of the welded joint in this material.

In fig. 3 shows the distribution of hardness over the section of the weld. It is clearly seen from the distribution that in the region of the transition from the weld material to the HAZ zone, a decrease in hardness values is observed even below the level of the hardness values of the base metal. The level of strength characteristics for these metals is practically the same.

The level of magnetic characteristics measured in the initial state on all the samples under study is also shown in Table 2. According to classical concepts, the level of magnetic properties correlates well with magnetic parameters [12]. The largest value of the coercive force (and the smallest for the residual induction and maximum magnetic permeability) is observed just for the weld material with the highest values of strength properties.

Table 2. Mechanical and magnetic properties of investigated materials

\begin{tabular}{|c|c|c|c|c|c|c|c|c|}
\hline Zone & $\sigma_{\mathrm{Y}},[\mathrm{MPa}]$ & $\sigma_{\mathrm{U}},[\mathrm{MPa}]$ & $\delta, \%$ & $\sigma_{\mathrm{Y}} / \sigma_{\mathrm{U}}$ & $\mathrm{HV}_{0,05}$ & $H_{\mathrm{c}},[\mathrm{A} / \mathrm{cm}]$ & $\left.B_{\mathrm{r},}, \mathrm{T}\right]$ & $\mu_{\max }$ \\
\hline Base metal & 595 & 650 & 14,7 & 0,91 & 260 & 7,1 & 1,125 & 744 \\
\hline Weld material & 640 & 710 & 14,8 & 0,90 & 320 & 10,6 & 1,063 & 544 \\
\hline HAZ metal & 600 & 680 & 14,2 & 0,88 & 235 & 7,1 & 1,127 & 760 \\
\hline
\end{tabular}

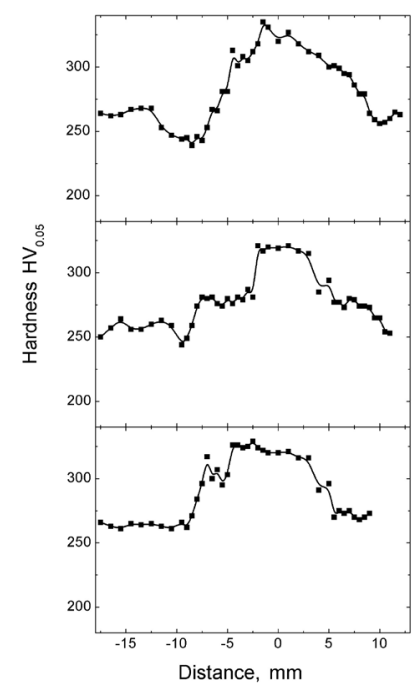

Fig. 3. The hardness distribution across the weld joint. The measurement lines are shown on Fig.1. 
Fig. 4 shows the field dependences of the differential magnetic permeability of the material of individual zones of the welded joint. It is clearly seen that the peaks from the HAZ material and the base metal are located in the same fields, since they have practically equal strength properties, and the values of their coercive forces coincide. The peak in the field dependence of the differential magnetic permeability, corresponding to the material of the weld of steel X80, lies in stronger fields, possibly due to the greater alloying and dispersion of the structure of this material. There by, the application of field dependences and it's parameters makes it possible to obtain the necessarily information about the state of individual components of the welded joint. If to compare with the information from main characteristics determined from the magnetic hysteresis loop $\left(H_{\mathrm{c}}\right.$, $B_{\mathrm{r}}$ and $\left.\mu_{\max }\right)$ - they reflect an integral state from the entire analyzed volume.

In fig. 5 shows the dependences of the magnetic characteristics on the level of applied normal stresses during elastic deformation.

As can be seen from Fig. 5, the values of the magnetic characteristics of the materials of the heat-affected zone and the base metal of the steel are approximately at the same level. The values of the coercive force of the weld metal, both in the initial state and in the entire range of applied stresses, exceed the values of the coercive forces for the base metal and HAZ material. Perhaps this is due to the greater dispersion of the structural components of the weld.

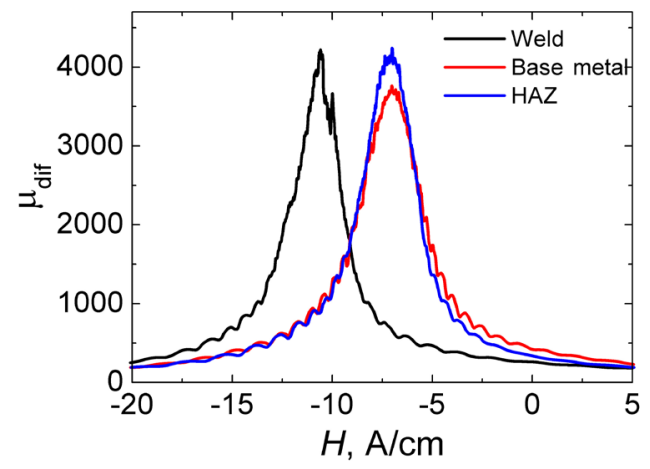

Fig. 4. Field dependences of differential magnetic permeability of different zone of welded pipe with strength grade X80.
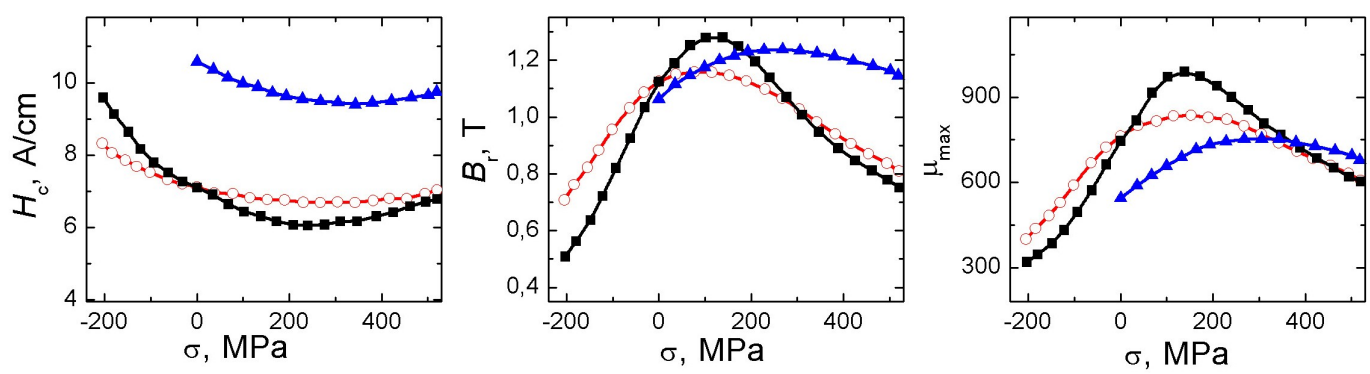

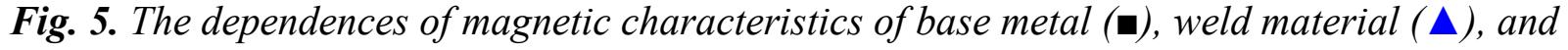
HAZ metal (O) on the normal applied stresses.

The dependences $H_{\mathrm{c}}(\sigma), B_{\mathrm{r}}(\sigma)$ and $\mu_{\max }(\sigma)$ of all the samples under study exhibit extrema in the region $\sigma \approx 150-250 \mathrm{MPa}$. The experimentally obtained non-monotonic dependence of $H_{\mathrm{c}}(\sigma)$, $B_{\mathrm{r}}(\sigma)$ and $\mu_{\max }(\sigma)$ in the elastic region can be represented as a result of the action of a number of 
factors. In particular, stretching of samples in the elastic region leads to the formation of a magnetic stress texture, also called induced magnetic anisotropy [13]. Thus, the studied magnetic characteristics of all investigated materials unambiguously change at normal stress values in the range from $-200 \mathrm{MPa}$ to $+200 \mathrm{MPa}$, and these parameters can be used for magnetic control of normal stresses and elastic deformations in trunk pipelines. It should be noted that the established range of applied stresses is several times higher than the working pressure for modern pipelines, which, according to [14], is 10-15 MPa.

\section{Conclusion}

It is shown that the weld material of the investigated steel has a greater dispersion in relation to the base metal, and even more so to the HAZ material, where a coarse-grained structure is formed.

It was found that the values of the field of the maximum differential permeability on the field dependences correlate with different structural states and the level of physical and mechanical properties of individual zones of welded joints. This can be the basis for further development of a methodology for diagnosing the deviation of the structure and level of physical and mechanical properties of the material from the required state and identifying the most dangerous zones of the welded joint from the point of view of the possibility of brittle fracture.

At the level of normal stresses from -200 to $200 \mathrm{MPa}$, not exceeding 0.4 of the yield point, the coercive force, residual induction and maximum magnetic permeability of the metal from all zones of the welded joint behave unambiguously, which makes it possible to use them as parameters for assessing the stress the deformed state of individual zones of welded joints of large-diameter pipes.

\section{Ackowledgement}

The research was partially supported by RFBR grant No. 20-08-00392_a. The equipment of the Plastometriya collective use center was used in the research.

\section{References}

[1] V.V. Rybin, V.V. Malyshevsky, E.I. Khlusova, V.V. Orlov, Y. Kh. Shakhpazov, Iu. D. Morozov, S. Yu. Nastich, M. Yu. Matrosov, High-strength steels for the main pipelines, Voprosy materialovadenia. 3(59) (2009) 127-137.

[2] Z.P. Zhao, G.Y. Qiao, G.P. Li, et al., Fatigue properties of ferrite/bainite dual-phase X80 pipeline steel welded joints, Sci Technol Weld Join. 22 (3) (2017) 217-226.

https://doi.org/10.1080/13621718.2016.1219120

[3] V.V. Rusakova., T.L. Lobanova, Prospects for the use of high-strength pipes of strength category K65 (X80) for long-distance gas transportation projects, Science and technique in gas industry. 1 (2009) 4-7.

[4] W. Qian, T. Han, Y. Wang, et al., Microstructure and mechanical properties of X80 girth welds with different welding processes, Mater Sci Forum. 4502 (1796) (2017) 1079-1087. https://doi.org/10.4028/www.scientific.net/MSF.898.1079

[5] Jie Ning, Zi-ShuYu, Kun Sun, Mei-Juan Hu, Li-Xu Zhang, Yan-Bin Zhang, Lin-Jie Zhang, Comparison of microstructures and properties of X80 pipeline steel additively manufactured based on laser welding with filler wire and cold metal transfer, Journal of Materials Research and Technology. 1-2 (2021), 752-768. https://doi.org/10.1016/j.jmrt.2020.12.021

[6] O.I. Sleptsov, A.V. Lyglaev, A.M. Bol'shakov, S.A. Sintsov, Diagnostics and safety of aging large mechanical systems operating under conditions of the far north: the problem and ways to 
solve it, Russian Journal of Nondestructive Testing. 6(44) (2008) 395-402.

https://doi.org/10.1134/S1061830908060053

[7] V.A. Kanaikin, V.E. Loskutov, A.F. Matvienko, B.V. Patramanskii, A pig introscope for inspection of main gas pipelines, Russian Journal of Nondestructive Testing. 7(43) (2007) 423426. https://doi.org/10.1134/S1061830907070017

[8] E.V. Poyarkova, On the issue of solving the problem of increasing the reliability of equipment in the oil and gas industry on the basis of quality control of welded joints, Neftegasovoe delo. 1(6) (2008) 278-283.

[9] D.I. Vichuzhanin, V.A. Khotinov, S.V. Smirnov, The effect of the stress state on the ultimate plasticity of steel X80, Diagnostics, Resource and Mechanics of Materials and Structures. 1 (2015) 73-89. https://doi.org/10.17804/2410-9908.2015.1.073-089

[10] L. Lan, C. Qiu, D. Zhao, et al., Analysis of microstructural variation and mechanical behaviors in submerged arc welded joint of high strength low carbon bainitic steel, Mater. Sci. Eng. A. 558 (2012) 592-601. https://doi.org/10.1016/j.msea.2012.08.057

[11] Y. Ci, Z.Z. Zhang, Simulation study on heat-affected zone of high-strain X80 pipeline steel, J. Iron. Steel Res. Int. 24 (9) (2017) 966-972. https://doi.org/10.1016/S1006-706X(17)30140-1 [12] V.E. Scherbinin, E.S. Gorkunov, Magnetic control of the metal quality, Ekaterinuburg, UB RAS, 1996.

[13] S.V. Vonsovski, Ya.S. Schur, Ferromagnetizm, Leningrad, OGIZ, 1948.

[14] A.V. Kushnarev, E.V. Shekhovtsov, E.S. Kapustina, S.A. Remigo, I.V. Kostenko, Production of pipe steel of strength classes X80 and X70, Steel in Translation. 6(38) (2008) 490491. https://doi.org/10.3103/S0967091208060168 